\title{
The Effect of Grazing Intensity on Vegetation Coverage and Nitrogen Mineralization Kinetics of Steppe Rangelands of Iran (Case Study: Nodoushan Rangelands, Yazd, Iran)
}

\author{
Zahra Karimipoor ${ }^{1}$, Anahita Rashtian ${ }^{1, *}$, Masoume Amirkhani ${ }^{2} \mathbb{D}$ and Somayeh Ghasemi ${ }^{1}$ \\ 1 School of Natural Resources and Desert Studies, Yazd University, Yazd 8915818411, Iran; \\ karimipoorzahra@yazd.ac.ir (Z.K.); s.ghasemi@yazd.ac.ir (S.G.) \\ 2 Cornell AgriTech, School of Integrative Plant Science, Horticulture Section, Cornell University, \\ Geneva, NY 14456, USA; ma862@cornell.edu \\ * Correspondence: arashtian@yazd.ac.ir
}

check for updates

Citation: Karimipoor, Z.; Rashtian, A.; Amirkhani, M.; Ghasemi, S. The Effect of Grazing Intensity on Vegetation Coverage and Nitrogen Mineralization Kinetics of Steppe Rangelands of Iran (Case Study: Nodoushan Rangelands, Yazd, Iran). Sustainability 2021, 13, 8392. https:// doi.org/10.3390/su13158392

Academic Editors: Pablo Peri and Marc A. Rosen

Received: 12 April 2021

Accepted: 22 July 2021

Published: 27 July 2021

Publisher's Note: MDPI stays neutral with regard to jurisdictional claims in published maps and institutional affiliations.

Copyright: (c) 2021 by the authors. Licensee MDPI, Basel, Switzerland. This article is an open access article distributed under the terms and conditions of the Creative Commons Attribution (CC BY) license (https:/ / creativecommons.org/licenses/by/ $4.0 /)$.

\begin{abstract}
Livestock grazing can affect the cycling of nutritional elements in soil by making changes to the vegetation coverage. This study aimed to investigate the effect of rangeland exploitation on vegetation coverage and nitrogen kinetics. To this end, three experimental sites of light, moderate, and heavy grazing in Nodoushan rangelands of Yazd province were selected. The vegetation properties were then measured through systematic random sampling method and three to five bases along the transect were sampled from the current year growth of the dominant plants in the region. The soil samples were collected from $0-15 \mathrm{~cm}$ depth in five replications and mixed together to obtain a single composite soil sample on each site. In the first stage, nitrogen (N), carbon $(\mathrm{C}), \mathrm{C} / \mathrm{N}$, cellulose, hemicellulose, and lignin of the sampled plant as well as nitrogen, carbon, lime, soil texture, saturation moisture percentage, $\mathrm{pH}$, and electrical conductivity (EC) of the soil were measured. As the soil properties did not differ for light and moderate grazing soils, different treatments were conducted on the dominant species of light and heavy grazing sites with $1 \%$ organic carbon added to the rangeland soil. Nitrogen mineralization treatments were selected based on vegetation changes that, with increasing livestock grazing intensity, changed the predominance of plant composition from Artemisia sieberi and steppe to percentage Artemisia sieberi and Peganum harmala. The treatments included control, 100\% Artemisia sieberi, 75\% Artemisia sieberi and 25\% Peganum harmala, 50\% Artemisia sieberi and 50\% Peganum harmala, 25\% Artemisia sieberi and 75\% Peganum harmala, and 100\% Peganum harmala. The soil samples were incubated for pure nitrogen mineralization in three replications of 3 months. The results of nitrogen mineralization revealed that the immobilization of the treated soil with higher Artemisia sieberi and lower Peganum harmala was done at a more rapid rate during the first week. The immobilization was slowly reduced by the third week and then followed a growing rate. Overall, the results show that an increase in grazing intensity was associated with a change in vegetation coverage toward Peganum harmala species, the biochemical characteristics of which elevated the levels of pure nitrogen mineralization in soil.
\end{abstract}

Keywords: livestock grazing; plant residue quality; nitrogen immobilization; nitrogen mineralization

\section{Introduction}

Livestock grazing is a major determinant of soil and vegetation that can affect the structure and function of vegetation coverage in many ways [1,2], for which it is necessary to establish a grazing plan for the conservation of these ecosystems and their plant species useful for livestock [3,4]. It can also influence the nutrient flows and the performance of rangeland ecosystems [5]. In most cases, livestock grazing leads to the abundance of plants that have a low rate of decomposition in the plant composition. This can be attributed to the fact that only those plants that contain deterrent texture such as lignin, kutins, and toxins are able to survive in the plant composition [5]. Among livestock grazing 
consequences are soil carbon increase and soaking due to growth stimulation [6] or soil carbon decrease due to loss of the photosynthetic part of the plant and a consequent increase in greenhouse gas emissions [7]. Additionally, livestock grazing may not significantly influence soil carbon content [6]. These reported differences or contradictions about the effect of grazing on the storage of soil nutrients-carbon and nitrogen in specific-can arise from the differences in climate, soil intrinsic properties, soil topography, plant community composition, livestock type, and different grazing management strategies with different intensities and durations [6-8]. In this regard, there are two hypotheses. The first is the acceleration hypothesis, which suggests that due to increased growth and stimulation of plant growth - the factor of increasing forage quality - grazing animals thus contribute to an increase in the rate of decomposition of litter and organic matter and an increase in the mineralization of elements. The second hypothesis is the reduction hypothesis, which states that grazers harvest plants selectively rather than randomly, and over time cause the dominance of low-quality plants in the long run. The rate of decomposition and mineralization of the elements in them is very low.

- The quantity and quality of soil organic matter are considered to be the most influential factors in soil nitrogen immobilization. The ability of soil to convert organic nitrogen into mineral nitrogen (the potential for nitrogen mineralization) is considered as an indicator of plant access to nitrogen in soil ecosystems [9]. Among the chemical and biochemical factors, nitrogen release is correlated with nitrogen content, $\mathrm{C} / \mathrm{N}$ ratio of organic materials, and the polyphenol/ $\mathrm{N}$ ratio of tropical legumes. Meanwhile, the ratio of lignin to nitrogen is better correlated with nitrogen release for tree litters [10]. Knowing the decomposition rate of plant residues, the soil microbial community, and organic materials is necessary to perceive the cycle of nutrients and to maintain soil quality and fertility as well as pasture sustainability [11-13]. Based on previous studies, the hypothesis of this research is that increasing the intensity of livestock grazing has been able to cause changes in vegetation and soil that have reduced the mineralization kinetics of nitrogen; as a result, the amount and speed of nitrogen available to plants is reduced in the soil. Therefore, this study aimed to investigate the effect of animal grazing intensity on changes in rangeland vegetation and then the effect on some soil biological activities in relation to the amount and rate of nitrogen mineralization kinetics, which is a good indicator for expressing the supply of nitrogen and soil fertility.

\section{Materials and Methods}

For this study, steppe grasslands of the Nodoushan area in Yazd province were selected. Nodoushan, a watershed with an area of $46,000 \mathrm{ha}$, is located in the west of Yazd province between longitudes $53^{\circ} 24^{\prime} 15^{\prime \prime} \mathrm{E}$ to $53^{\circ} 48^{\prime} 36^{\prime \prime} \mathrm{E}$ and latitudes $31^{\circ} 45^{\prime} 16^{\prime \prime} \mathrm{N}$ to $32^{\circ} 17^{\prime} 23^{\prime \prime}$ $\mathrm{N}$ (Figure 1). The study area is located in the altitude range of 1900 to $3400 \mathrm{~m}$ above sea level and the slope range from zero to 80 percent [11]. According to the statistics of the last 10 years, the number of days with zero and less than zero temperatures is 85 days, and the average maximum and minimum temperatures are 22.3 and 7 degrees Celsius, respectively. The average annual rainfall is $124 \mathrm{~mm}$, and also, according to the Ambrotic curve, the length of the dry season is 8 months, which lasts from early April to early December and has shallow to deep soils. They are relatively well-matched with round river rocks, and the herd grazing in this range is a mixture of goats and sheep, of which about $10 \%$ of the livestock are sheep [14]. 


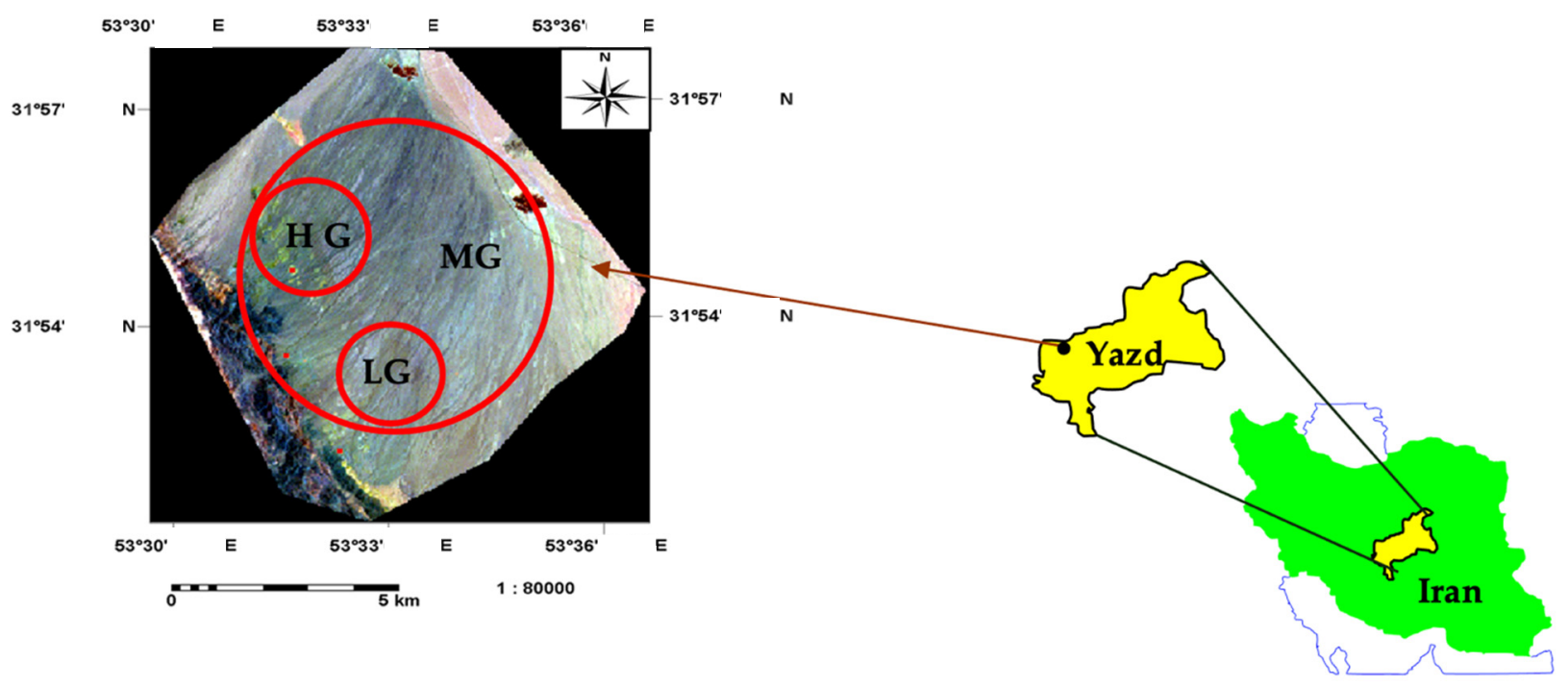

Figure 1. Location of the study area in Iran and Yazd province along with the location of sampling sites (HG: Heavy Grazing, MG: Moderate Grazing, LG: Light Grazing).

\subsection{Vegetation Coverage}

The study area was first developed on a topographic map with a scale of 1:25,000, and then the study sites were determined including light, moderate, and heavy grazing grasslands. The intensity of grazing was considered based on previous studies in the same area. The area enclosed in barbed wire, which was used only in special conditions, such as the end of the season, was selected as a light grazing area, and the area around the fountain used by livestock every day twice was selected as a high grazing intensity. Some field visits each grazing site were arranged, and the number of plots was obtained from the statistical method $N=t^{2} s^{2} / p^{2} x^{2}$. In this formula, $N$ equals the number of required samples, $t$ is extracted from the $t$-Student table with the desired probability level $(10 \%), x$ is the mean of the primary sample, $p$ shows the error range usually between +0.1 and -0.1 , and $s^{2}$ is the variance of primary samples. In the vegetation study of grassland sites, $2 \mathrm{~m}^{2}$ squares were used as a suitable pattern for plant distribution in steppe regions [15-17]. After identifying study units, vegetation sampling was done using plots of $2 \mathrm{~m}^{2}$ area along a transect of $50 \mathrm{~m}$ length in the region. The number of plots deployed at each study site was about 60 plots on 20 transects. The percentage of vegetation coverage and production (cutting and weighing method) of each genus within each plot were measured for the three light, moderate, and heavy grazing sites (Figure 2).
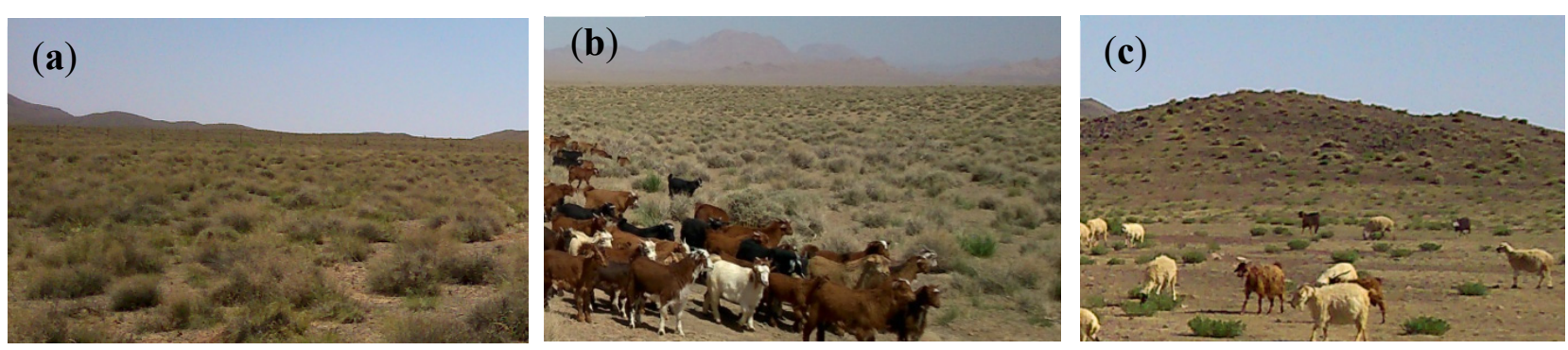

Figure 2. Overview of the area (a) light grazing sites (b) moderate grazing sites (c) heavy grazing sites. 


\subsection{Soil and Plant Sampling and Analysis}

Soil samples were collected from a depth of $0-15 \mathrm{~cm}$. For each plot, five samples were taken at the ending points of transects and mixed together to reach a single composite soil sample. Soil texture was determined by hydrometry [18]. Electrical conductivity (EC) and $\mathrm{pH}$ were estimated in the saturation extract [18]. The percentage of organic carbon and the percentage of total nitrogen were respectively measured using wet oxidation by the addition of potassium bichromate and concentrated sulfuric acid agents [19] and autocollector model 3200 by the Caldwell method [20]. The amount of moisture saturation percentage (SP) was measured by the weight method [18]. Plant sampling was performed on the predominant species in terms of general physiognomy. Then, three to five bases were randomly harvested along each transect. Due to the lack of production and to reduce harm to the bases, the samples were mixed together and considered as a single composite sample. All the plant samples were washed and air-dried and then ground. Similar to soil samples, organic carbon and total nitrogen percentages were measured for the selected residues. The level of cellulose, hemicellulose, and lignin was also determined by means of the Goering and Van Soest method [21] using neutral and acidic detergents.

\subsection{Treatment Design}

According to the results of the effect of livestock grazing on vegetation and soil, the treatments were selected based on the fact that due to the increase in livestock grazing intensity, the plant composition had changed so that from Artemisia sieberi Besser and Stipa barbata Desf. dominance to Artemisia sieberi Besser, Stipa barbata Desf. had changed, and given that Artemisia sieberi Besser, Stipa barbata Desf., and Peganum harmala L. constituted over $75 \%$ of the region vegetation coverage [22], the $\mathrm{C} / \mathrm{N}$ ratio was calculated for each genus, showing no significant difference between Artemisia sieberi and Stipa barbata. Covering most of the pasture [23], Artemisia sieberi was adopted in addition to Peganum harmala as the plant samples with which to study the effect of pasture exploitation on the kinetics of carbon and nitrogen decomposition. Since there was no significant difference between the light and moderate grazing sites in terms of physical and chemical properties, the following treatments were imposed on the light and heavy grazing soils in nitrogen mineralization experiments with 3 replications. Then light and heavy soils with $1 \%$ organic carbon [24] added to aerial organs of the plants of Artemisia sieberi and Peganum harmala were treated by control, $100 \%$ Artemisia sieberi, $75 \%$ Artemisia sieberi $25 \%$ Peganum harmala, 50\% Artemisia sieberi, 50\% Peganum harmala, 25\% Artemisia sieberi 75\% Peganum harmala, and $100 \%$ Peganum harmala treatment.

\subsection{Nitrogen Mineralization Kinetics}

For this purpose, $50 \mathrm{~g}$ of the studied soils were mixed with the plant residues to the extent of $1 \%$ by weight increase in soil organic carbon. Next, distilled water was gradually sprayed on the soil and plant residues to the extent required for a $50 \%$ increase in water retention moisture. The moist soils were then placed in polyethylene containers with a volume of $250 \mathrm{~mL}$. Afterwards, all the samples were incubated at $25^{\circ} \mathrm{C}$ for three months, during which the lost moisture was supplied by adding distilled water and bringing the original weight to the samples. At the end of the incubation period, the treated soil samples were extracted with $2 \mathrm{M} \mathrm{KCL}$. The mineralized nitrogen was measured using the steam distillation method. Mineralization or pure immobilization ( $\mathrm{Nm} / \mathrm{i}$ ) was obtained from the following equation:

$$
\mathrm{N}_{\mathrm{M} / \mathrm{I}}=\left(\mathrm{NH}_{4}-\mathrm{N}+\mathrm{NO}_{3}-\mathrm{N}\right)_{\text {final }}-\left(\mathrm{NH}_{4}-\mathrm{N}+\mathrm{NO}_{3}-\mathrm{N}\right)_{\text {initial }}
$$

During this period, the content of mineralized nitrogen was obtained for 1, 2, 3, 4, 6, 8, $10,12,14,18$, and 22 weeks after the start of incubation [24]. In order to measure potassium chloride-extractable nitrogen, the content of nitrogen extracted in the dry soi samples was measured using the method proposed by [24]. 


\subsection{Statistical Analysis}

Before statistical analysis, all data obtained were examined by a Kolmogorov-Smirnov test to ensure their normality. Then, a completely randomized design was used to compare each index for the effect of grazing on vegetation and soil and factorial design in a completely random format for investigating the mineralization of nitrogen over time. Thus, Duncan's test was used to compare the means using SPSS 22 software.

\section{Results}

\subsection{Vegetation Investigation in the Studied Grasslands}

The results show that the highest vegetation coverage and production belong to Artemisia sieberi. Due to the recent droughts and lack of rainfall, [22] there was no significant difference between light and moderate grazing sites in Artemisia sieberi coverage. After Artemisia sieberi, Lactuca orientalis (Boiss.) Boiss, Astragalus bisulcatus (Hook.) A. Gray, and Hertia angustifolia (DC.) Kuntze had the highest production in the light grazing site, respectively [11]. Among grass species, Stipa barbata and then Poa annua L. had the highest production and coverage, reducing at higher grazing intensities as becoming closer to the water trough. Among the species, Peganum harmala had the highest production and coverage at higher grazing intensities, as it was not appealing enough for grazing in the water trough (Table 1). Poa annua, the most appealing grass for grazing, was declining in this grassland. Artemisia sieberi, Stipa barbata, Lactuca orientalis, and Astragalus were the second most appealing plants. Peganum harmala as the third most appealing plant for grazing had the highest production and coverage in the water trough and is classified as an invasive species.

Table 1. List of plants within the measured plots in the study area.

\begin{tabular}{|c|c|c|c|c|c|c|}
\hline \multirow{2}{*}{ Vegetation Genus } & \multicolumn{3}{|c|}{ Vegetation Coverage (\%) } & \multicolumn{3}{|c|}{ Production * $\left(\mathrm{g} / \mathrm{m}^{2}\right)$} \\
\hline & Light & Moderate & Heavy & Light & Moderate & Heavy \\
\hline Artemisia sieberi & $5.37^{\mathrm{a}}$ & $6.65^{a}$ & $3.46^{\mathrm{b}}$ & 2.94 & 4.9 & 2.34 \\
\hline Stipa barbata & $4.79^{\mathrm{a}}$ & $2.77^{a b}$ & $0.46^{\mathrm{b}}$ & 7.37 & 1.42 & 0.61 \\
\hline Peganum harmala & 0 & 0 & 2.84 & 0 & 0 & 1.85 \\
\hline Poa annua & $2.02^{\mathrm{a}}$ & $0.75^{b}$ & $0.11^{\mathrm{c}}$ & $2.53^{\mathrm{a}}$ & $1.59^{b}$ & $0.4^{\mathrm{c}}$ \\
\hline Iris kemaonensis & $1.83^{\mathrm{a}}$ & $0.57^{\mathrm{b}}$ & $0.01^{\mathrm{c}}$ & $6.11^{\mathrm{a}}$ & $3.2^{b}$ & $046^{c}$ \\
\hline Lactucavirusa & $0.38^{b}$ & $0.18^{b}$ & $1^{\mathrm{a}}$ & $0.66^{\mathrm{b}}$ & $0.35^{\mathrm{b}}$ & $1.18^{\mathrm{a}}$ \\
\hline Astragalus bisulcatus & $0.27^{\mathrm{a}}$ & $0.21^{\mathrm{a}}$ & $0.12^{b}$ & $0.31^{\mathrm{a}}$ & $0.23^{b}$ & $0.08^{c}$ \\
\hline Hertia Angustifolia & $0.44^{\mathrm{a}}$ & $0.25^{\mathrm{a}}$ & 0 & $0.11^{\mathrm{a}}$ & $0.22^{\mathrm{a}}$ & 0 \\
\hline Jacobaea maritima & $0.92^{\mathrm{a}}$ & $0.55^{\mathrm{a}}$ & 0 & $0.65^{\mathrm{a}}$ & $0.59^{\mathrm{a}}$ & 0 \\
\hline Cirsium arvense & 0.04 & 0 & 0 & 0.055 & 0 & 0 \\
\hline Total & $16.02^{\mathrm{a}}$ & $11.72^{\mathrm{ab}}$ & $8.17^{\mathrm{c}}$ & $20.80^{\mathrm{a}}$ & $12.5^{\mathrm{b}}$ & $6.92^{c}$ \\
\hline Ratio of the first three plants to the total & 0.65 & 0.78 & 0.71 & 0.52 & 0.560 & 0.70 \\
\hline
\end{tabular}

${ }^{*}$ dry weight. The letters $\mathrm{a}, \mathrm{b}$ and $\mathrm{c}$ indicate statistically significant difference at $p<0.05$ within each row for vegetation coverage and production separately.

Using Duncan's test, the results of analysis of variance and means comparison suggested that there were significant differences between light, moderate, and heavy grazing sites in the production and percentage of vegetation coverage. Three Artemisia sieberi, Stipa barbata, and Peganum harmala covered nearly $70 \%$ of vegetation in three regions and included an average of $60 \%$ production of the total study area (Table 1 ).

There was no significant difference between the three plant species in the mean organic carbon content. The highest $\mathrm{C} / \mathrm{N}$ level of 39.64 was observed in Stipabarbata, not significantly different from its lowest level in Artemisia sieberi. Peganum harmala and Artemisia sieberi were selected for mineralization of carbon and nitrogen in the treatments concerning the higher production and coverage percentage of Artemisia sieberi compared with Stipa barbata in all three experimental sites. The total content of cellulose, hemicellulose, and lignin in Artemisia sieberi was higher than Peganum harmala (Table 2). 
Table 2. Mean comparison of the chemical and biochemical properties of Artemisia sieberi, Stipa barbata, and Peganum harmala.

\begin{tabular}{|c|c|c|c|c|c|c|c|c|c|}
\hline Plant Residue & OC & TN & CEL & HE & LG & $C: N$ & CEL:N & HE:N & LG:N \\
\hline Artemisia & $43.74^{\mathrm{a}}$ & $1.13^{b}$ & $33.16^{a}$ & $15.16^{b}$ & $17.06^{\mathrm{a}}$ & $38.64^{a}$ & $29.29^{a}$ & $13.39^{b}$ & $15.07^{\mathrm{a}}$ \\
\hline Stipa & $43.93^{\mathrm{a}}$ & $1.11^{b}$ & $28.06^{b}$ & $30.16^{a}$ & $10.63^{c}$ & $39.64^{a}$ & $25.30^{b}$ & $27.19^{a}$ & $9.58^{b}$ \\
\hline Peganum & $42.38^{a}$ & $2.70^{a}$ & $3.63^{c}$ & $11.53^{c}$ & $13.36^{b}$ & $15.68^{b}$ & $1.34^{\mathrm{c}}$ & $4.26^{\mathrm{c}}$ & $4.94^{c}$ \\
\hline
\end{tabular}

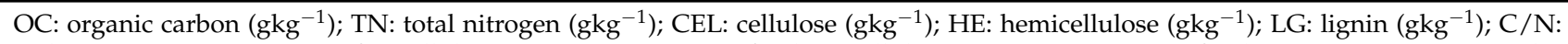
carbon-to-nitrogen ratio; $\mathrm{CEL} / \mathrm{N}$ : cellulose-to-nitrogen ratio; $\mathrm{HE} / \mathrm{N}$ : hemicellulose-to-nitrogen ratio; LG/N: lignin to-nitrogen ratio. The letters $\mathrm{a}, \mathrm{b}$ and $\mathrm{c}$ indicate statistically significant difference at $p<0.05$ within each column.

\subsection{Soil Properties of Study Area}

The soil texture of all three sites is composed of loamy sand. There was no significant difference between all three soils in the level of $\mathrm{pH}$ and lime, whilst the rate of EC of moderate grazing soil was significantly lower than that of heavy grazing soil (Table 3). Since the light grazing site had a higher coverage percentage and production than the moderate grazing site, the soils of light and heavy grazing sites were selected to study the process of nitrogen kinetics.

Table 3. Mean comparison of physical and chemical properties of the studied grassland soils.

\begin{tabular}{ccccccc}
\hline Region & Texture & OC & TN & pH & EC & Lime \\
\hline Light Grazing & Loamy sandy & $0.73^{\mathrm{a}}$ & $0.68^{\mathrm{a}}$ & $7.24^{\mathrm{a}}$ & $922^{\mathrm{b}}$ & $21.66^{\mathrm{a}}$ \\
Moderate Grazing & Loamy sandy & $0.66^{\mathrm{a}}$ & $0.14^{\mathrm{b}}$ & $7.24^{\mathrm{a}}$ & $996^{\mathrm{b}}$ & $21.5^{\mathrm{a}}$ \\
Heavy Grazing & Loamy sandy & $0.17^{\mathrm{b}}$ & $0.37^{\mathrm{b}}$ & $7.24^{\mathrm{a}}$ & $1318.9^{\mathrm{a}}$ & $22.33^{\mathrm{a}}$ \\
\hline
\end{tabular}

OC: organic carbon $\left(\mathrm{gkg}^{-1}\right)$; TN: total nitrogen $\left(\mathrm{gkg}^{-1}\right)$; EC: electrical conductivity; $\mathrm{pH}$ : acidity; $\mathrm{pH}$ and EC were measured in the saturated extract. The letters $\mathrm{a}$ and $\mathrm{b}$ indicate statistically significant difference at $p<0.05$ within each column.

3.3. Nitrogen Mineralization in the Residues of Artemisia sieberi and Peganum harmala in Light and Heavy Grazing Sites

As residues of Artemisia sieberi are poor in total nitrogen storage, containing high ratios of carbon to nitrogen as well as lignin to nitrogen (Table 2), they are less able to be decomposed. To meet its needs, a soil microorganism community takes nitrogen from the soil and converts it to organic nitrogen in the microbial biomass. Increased carbon dioxide production in the first week of incubation was indicative of a large community of decomposer microbes (Figure 3). Comparing the time procedure of nitrogen mineralization at different percentages of Artemisia sieberi with that of Peganum harmala residues (Figure 4) at the start of incubation, it can be seen that the mineralized nitrogen was much more strongly reduced under the treatments containing more Artemisia sieberi than Peganum harmala. Over time, this difference became more evident, showing pure nitrogen mineralization for the residues of $100 \%$ Artemisia sieberi that contained more nitrogen content and lower C/N ratio compared with residues of $100 \%$ Peganum harmala.

The kinetics of nitrogen mineralization in heavy grazing soil was also influenced by different percentages of Artemisia sieberi and Peganum harmala in plant residues (Figure 3). 


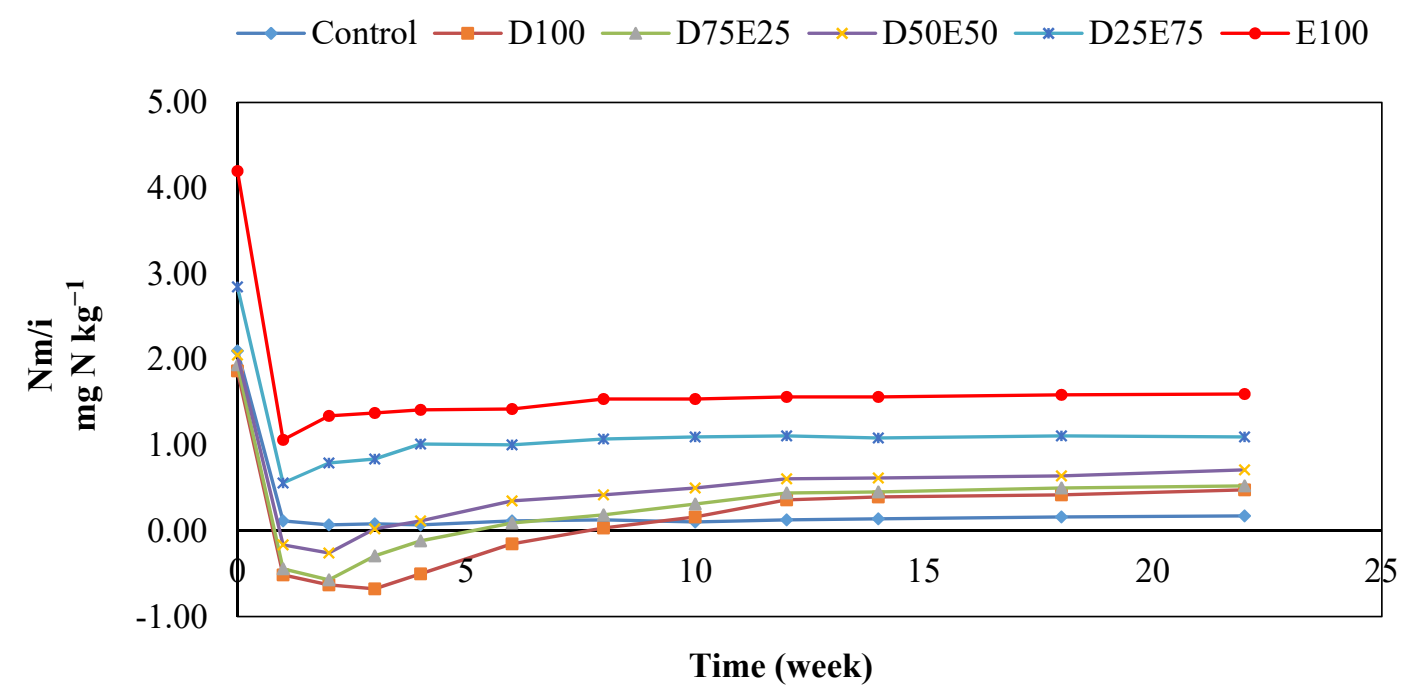

Figure 3. Nitrogen mineralization process for light grazing soil. 100E: 100\% Peganum harmala; D25E75: 25\% Artemisia sieberi 75\% Peganum harmala; D50E50: 50\% Artemisia sieberi 50\% Peganum harmala; D75E25: 75\% Artemisia sieberi 25\% Peganum harmala; D100: 100\% Artemisia sieberi; Control: control treatment.

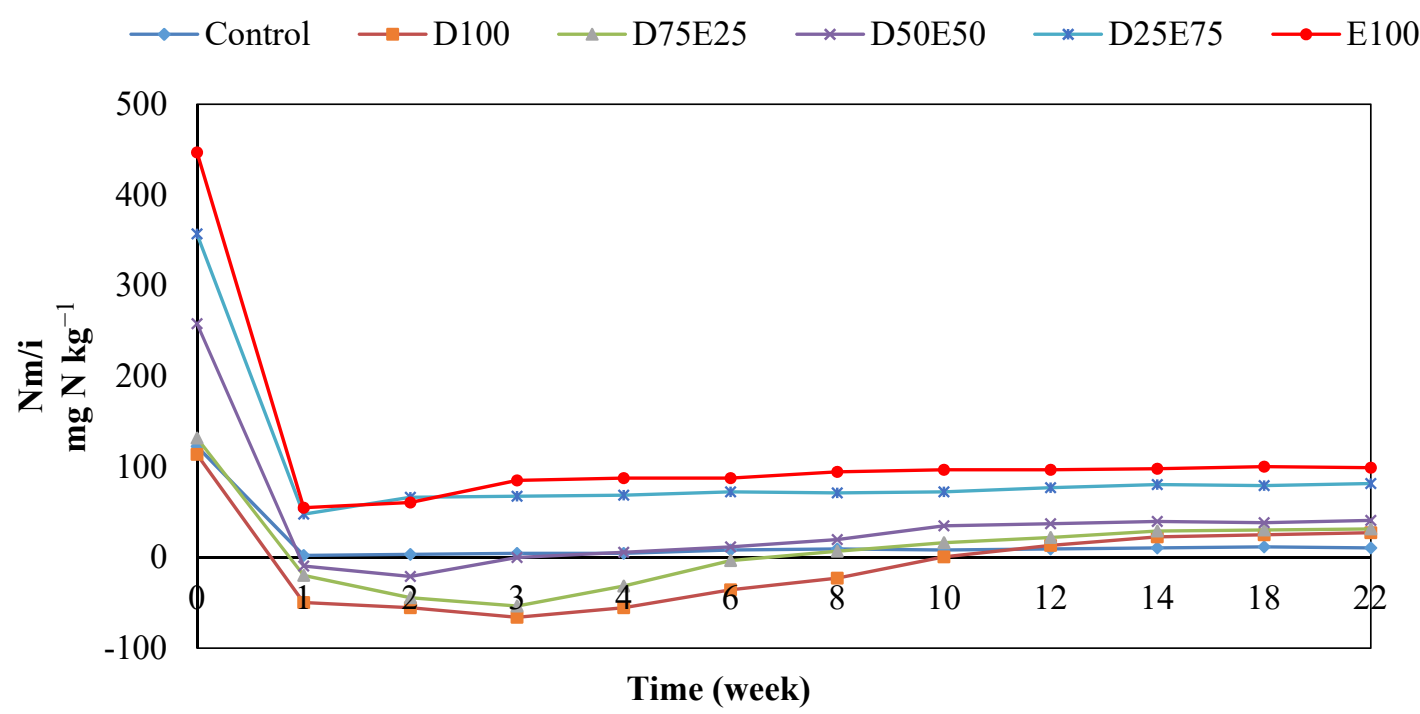

Figure 4. Nitrogen mineralization process for heavy grazing soil. 100E: 100\% Peganum harmala; D25E75: 25\% Artemisia sieberi 75\% Peganum harmala; D50E50: 50\% Artemisia sieberi 50\% Peganum harmala; D75E25: 75\% Artemisia sieberi 25\% Peganum harmala; D100: 100\% Artemisia sieberi; Control: control treatment.

The results of the analysis of variance in the light grazing soil show that there was a significant effect of time and plant residues as well as their interaction on (Nm/i) (Table 4). The positive values of $\mathrm{Nm} / \mathrm{i}$ indicate pure nitrogen mineralization, and the negative values of $\mathrm{Nm} / \mathrm{i}$ indicate pure nitrogen immobilization.

Table 4. Variance analysis of the effect of incubation time and different percentages of Artemisia sieberi and Peganum harmala residues on the pure nitrogen in the light grazing soil.

\begin{tabular}{cccc}
\hline Change Resources & Degree of Freedom & Mean Square & $\boldsymbol{F}$ \\
\hline Plant residues & 11 & $71,134.927$ & $279.165^{* *}$ \\
Time & 5 & $138,817.159$ & $46.237^{* *}$ \\
Plant time & 55 & 1227.837 & $4.301^{* *}$ \\
Error & 144 & 285.49 & \\
\hline
\end{tabular}

** Significance at $1 \%$. 
The highest mineralization of nitrogen (250.05 gr nitrogen per kilogram of soil) corresponds to week zero and before the start of incubation. It was sharply decreased up to the second week and then went up by the 22nd week (Figure 5).

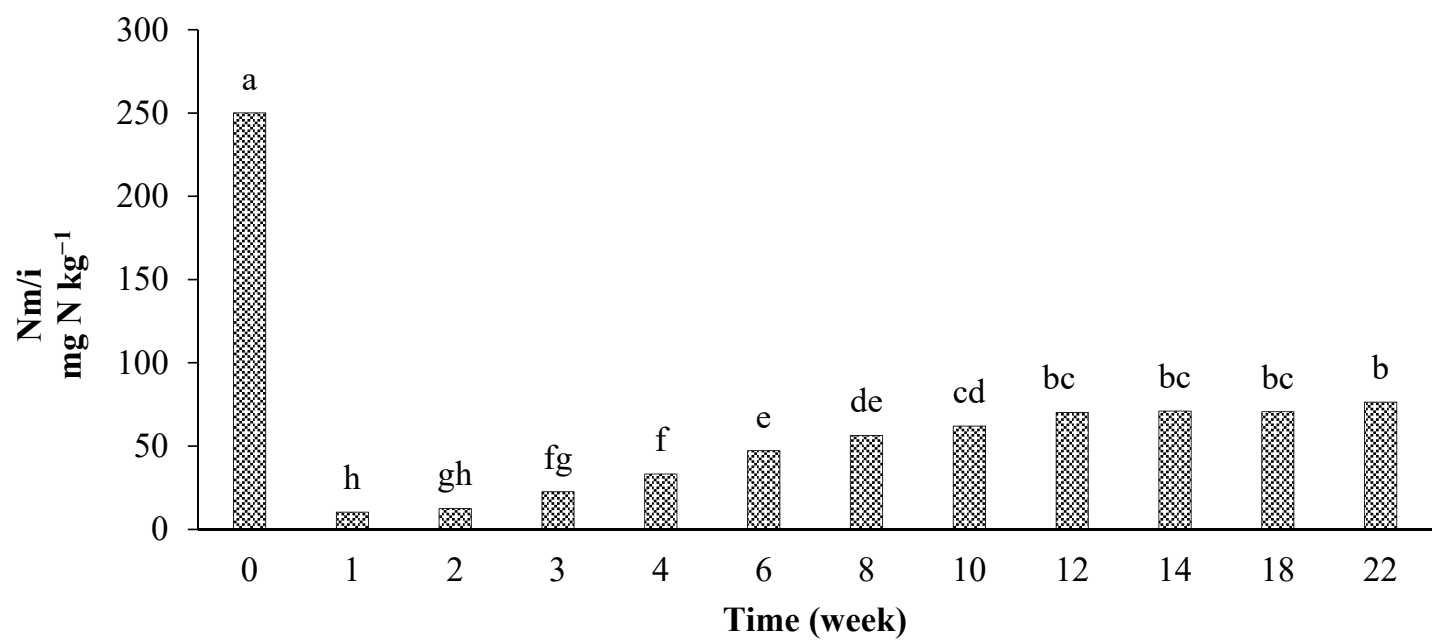

Figure 5. Mean comparison of the main effect of time on pure nitrogen mineralization in the light grazing site. Bars with no common letters are significantly different $(p<0.05)$.

In all comparisons, the larger values of $\mathrm{Nm} / \mathrm{i}$ correspond to the plant residues containing higher nitrogen and lower $\mathrm{C} / \mathrm{N}$ ratio. Regarding the obtained Nm/i for Peganum harmala residues, it seems that the total nitrogen content and $\mathrm{C} / \mathrm{N}$ ratio were more influential than other chemical and biochemical properties (Figure 6).

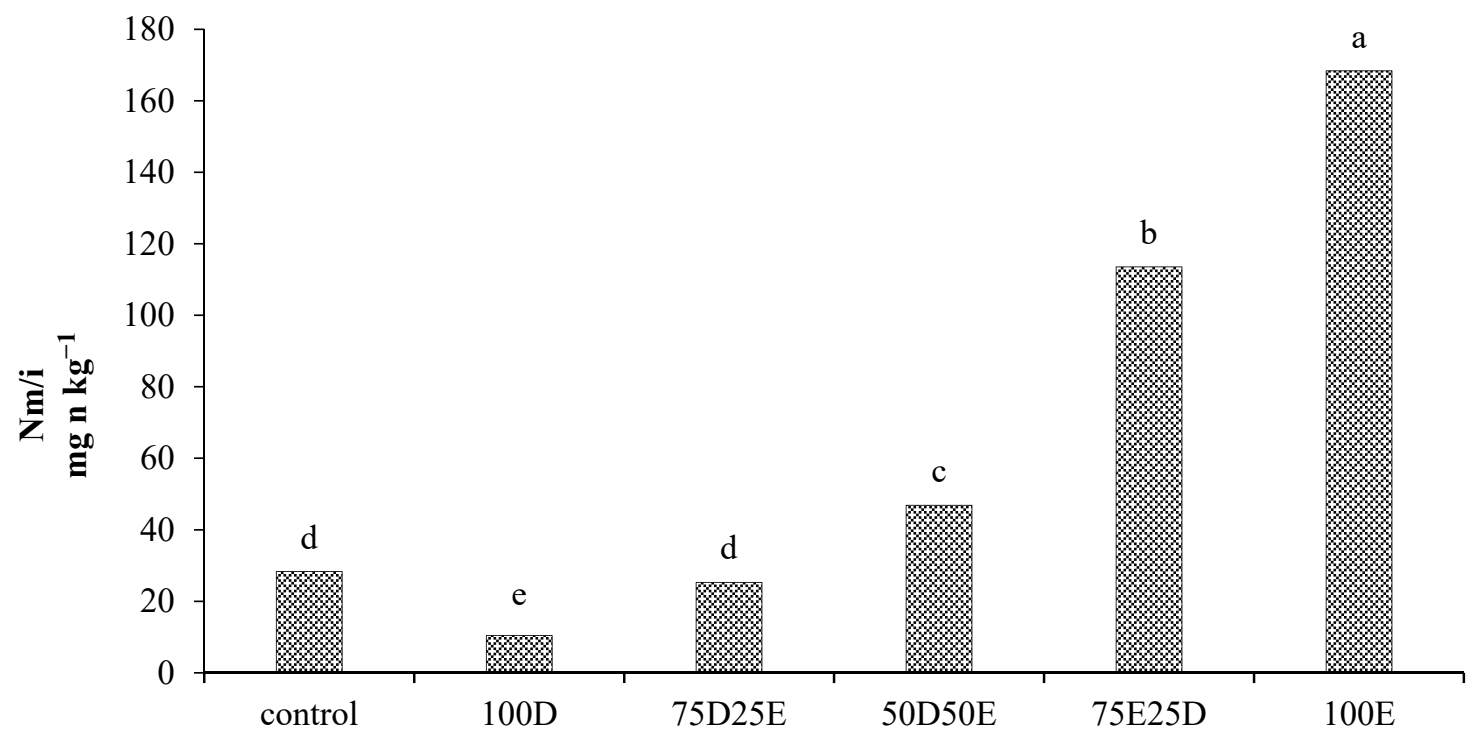

Figure 6. Mean comparison of the main effect of treatments on pure nitrogen mineralization in the light grazing site. 100E: 100\% Peganum harmala; D25E75: 25\% Artemisia sieberi 75\% Peganum harmala; D50E50: 50\% Artemisia sieberi 50\% Peganum harmala; D75E25: 75\% Artemisia sieberi 25\% Peganum harmala; D100: 100\% Artemisia sieberi; Control: control treatment. Bars with no common letters are significantly different $(p<0.05)$. 
The highest and the lowest pure nitrogen mineralization took place for $100 \% \mathrm{Pe}$ ganum harmala with $420 \mathrm{gr} \mathrm{N}$ per $\mathrm{kg}$ soil in week zero and $100 \%$ Artemisia sieberi with 67.66 gr N per kg soil in week two of incubation (Figure 7).

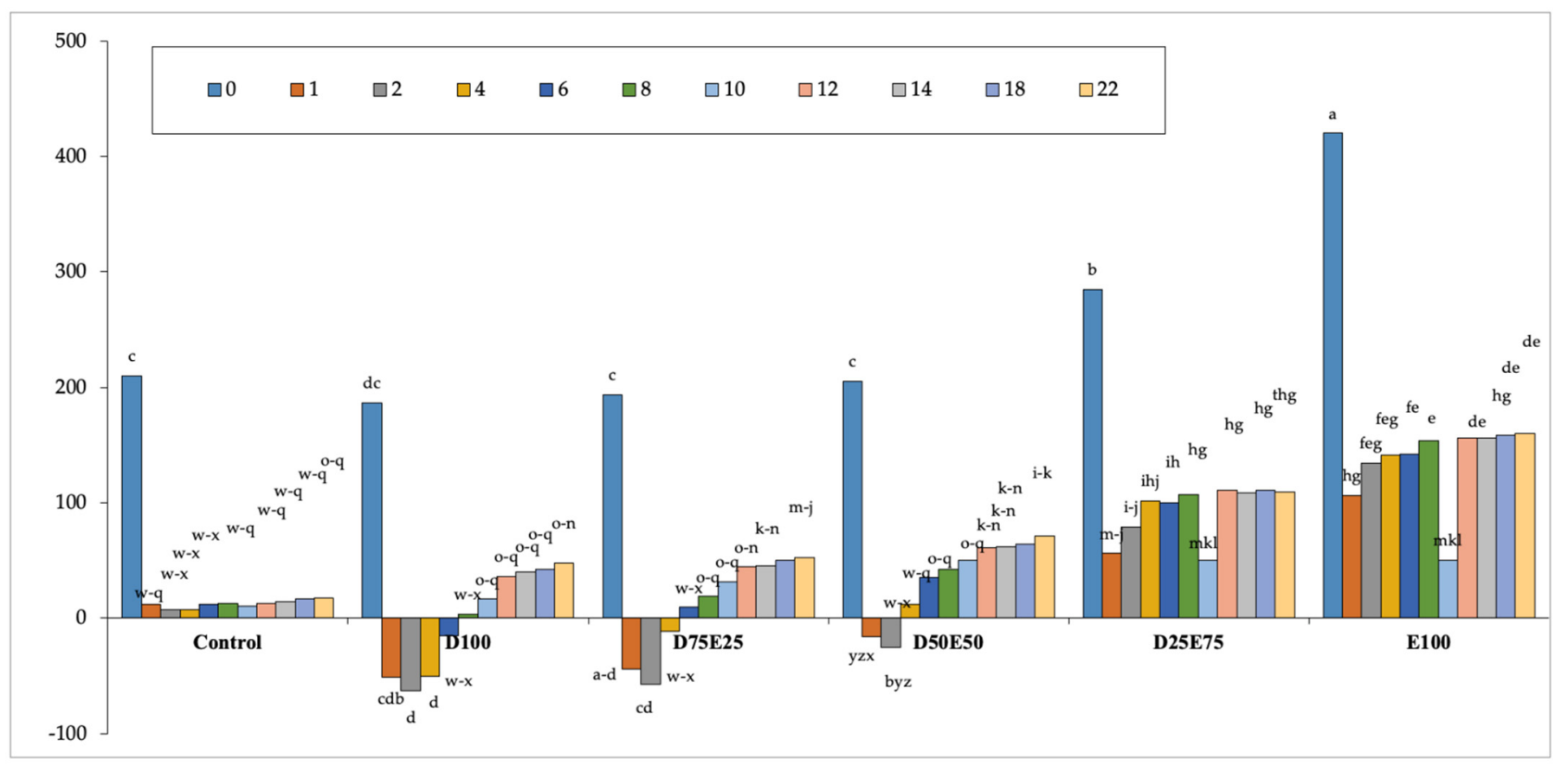

Figure 7. The interrelation of time and treatments with the process of pure nitrogen mineralization in the light grazing soil. 100E: 100\% Peganum harmala; D25E75: 25\% Artemisia sieberi 75\% Peganum harmala; D50E50: 50\% Artemisia sieberi 50\% Peganum harmala; D75E25: 75\% Artemisia sieberi 25\% Peganum harmala; D100: 100\% Artemisia sieberi; Control: control treatment. Bars with no common letters are significantly different $(p<0.05)$.

The results of the analysis of variance in the heavy grazing soil show that there was a significant effect of time, plant residues, as well as their interaction on pure nitrogen mineralization (Table 5).

Table 5. Variance analysis of the effect of plant residues and time on pure nitrogen in heavy grazing site.

\begin{tabular}{cccc}
\hline Change Resources & Degree of Freedom & Mean Square & $\boldsymbol{F}$ \\
\hline Time & 11 & $72,259.000$ & $256.000^{* *}$ \\
Plant residues & 5 & $90,101.000$ & $319.000^{* *}$ \\
Plant time & 55 & 3088.000 & $10.000^{* *}$ \\
Error & 144 & 282.000 & \\
\hline
\end{tabular}

** Significance at $1 \%$.

The positive values of $\mathrm{Nm} / \mathrm{i}$ are indicative of pure nitrogen mineralization, and the negative values of $\mathrm{Nm} / \mathrm{i}$ are indicative of pure nitrogen immobilization. The highest and the lowest mineralization of 238 and $1 \mathrm{gr}$ of $\mathrm{N}$ per $\mathrm{kg}$ of soil occurred in the zero and third weeks, respectively (Figure 8). The highest and the lowest Nm/i of 117 and $-6 \mathrm{gr} \mathrm{N} / \mathrm{kg}$ soil belonged to $100 \%$ Peganum harmala and $100 \%$ Artemisia sieberi treatments, respectively. 


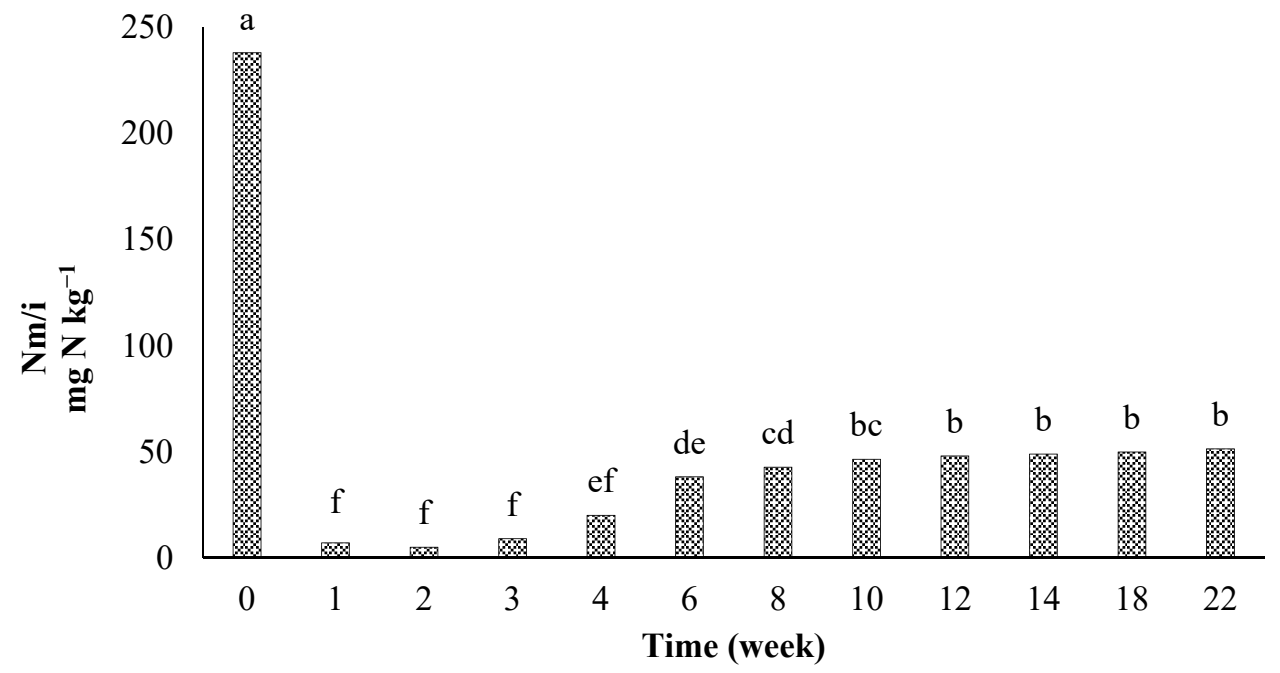

Figure 8. Mean comparison of the main effect of time on pure nitrogen in the heavy grazing site. Bars with no common letters are significantly different $(p<0.05)$.

The results from the interrelation of plant residues, time, and pure nitrogen mineralization in heavy grazing soil suggest that the highest and the lowest pure mineralization values of 446.83 and $65.92 \mathrm{gr} \mathrm{N} / \mathrm{kg}$ soil respectively correspond to $100 \%$ Peganum harmala in week zero and $100 \%$ Artemisia sieberi in week three (Figures 9 and 10).

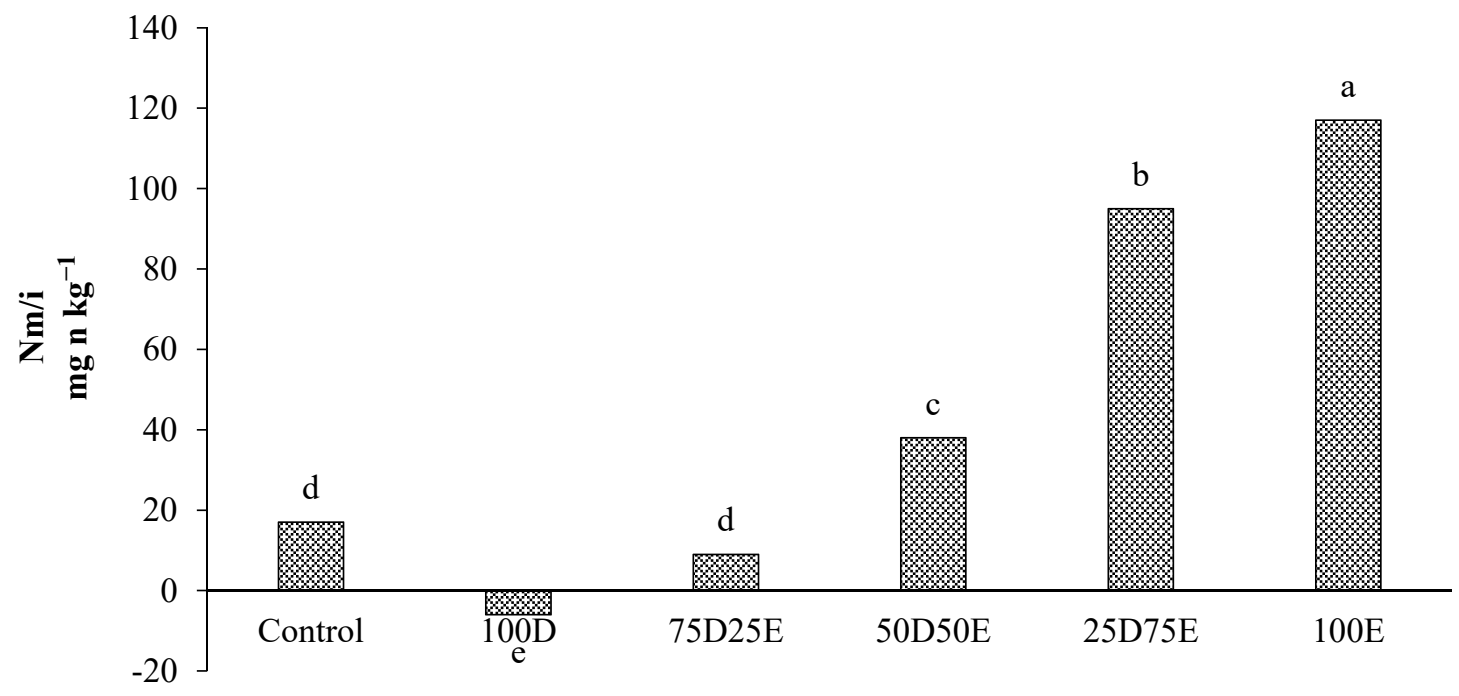

Figure 9. Mean comparison of the main effect of the plant residues on pure nitrogen in the heavy grazing site. $100 \mathrm{E}: 100 \%$ Peganum harmala; D25E75: 25\% Artemisia sieberi 75\% Peganum harmala; D50E50: 50\% Artemisia sieberi 50\% Peganum harmala; D75E25: 75\% Artemisia sieberi 25\% Peganum harmala; D100: 100\% Artemisia sieberi; Control: control treatment. Bars with no common letters are significantly different $(p<0.05)$. 


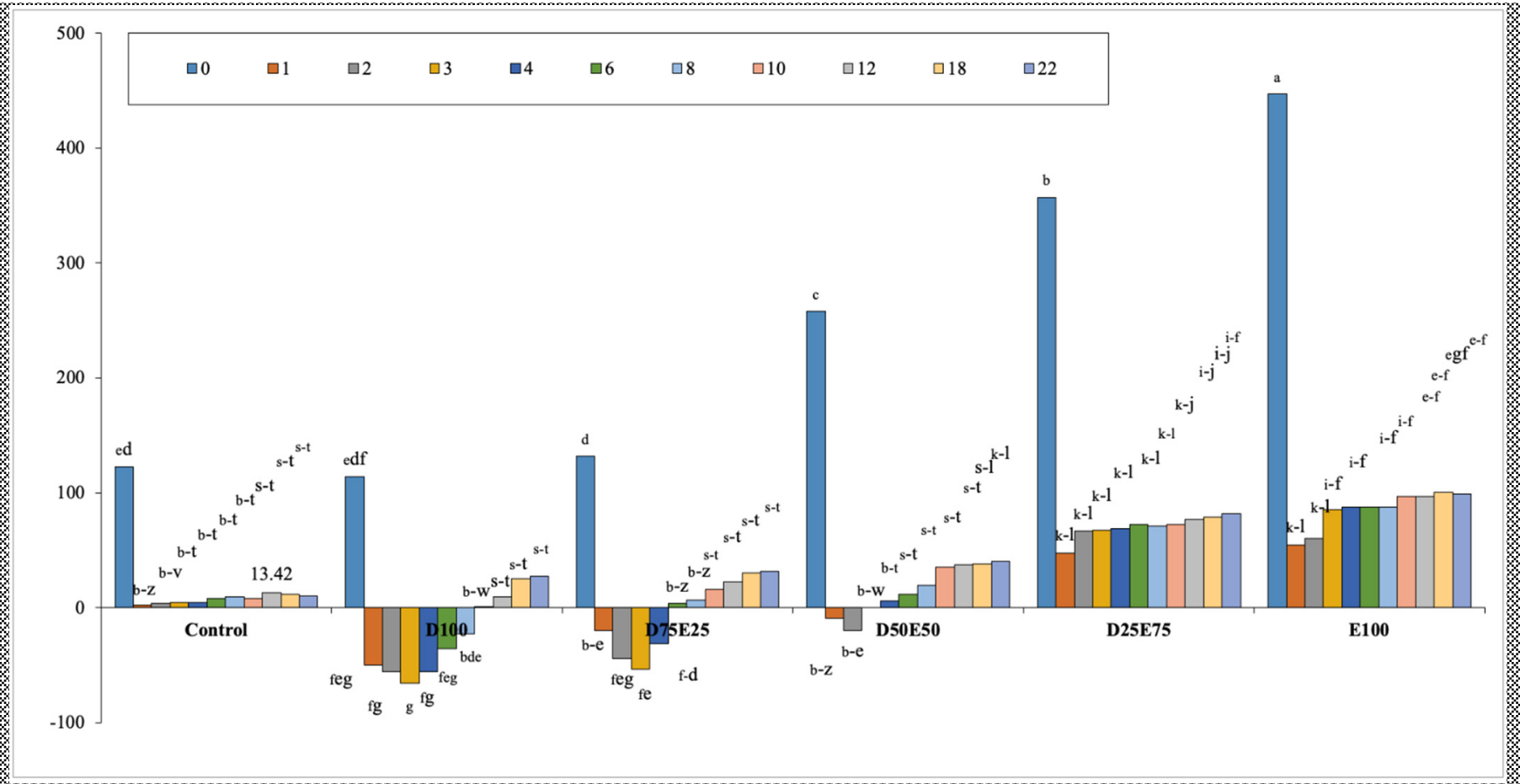

Figure 10. The interaction of time and treatments with the process of pure nitrogen mineralization in the heavy grazing soil. 100E: 100\% Peganum harmala; D25E75: 25\% Artemisia sieberi 75\% Peganum harmala; D50E50: 50\% Artemisia sieberi 50\% Peganum harmala; D75E25: 75\% Artemisia sieberi 25\% Peganum harmala; D100: 100\% Artemisia sieberi; Control: control treatment. Bars with no common letters are significantly different $(p<0.05)$.

\section{Discussion}

The results of the present study suggest that in spite of short distance, light grazing includes more varied species and thus richer vegetation than the moderate and heavy grazing grasslands. The lack of vegetation in heavy grazing grassland is suggestive of the removal of species from the flora list due to continuous grazing as well as the existence of unappealing plants including Peganum harmala in the water trough.

Gholami et al. [25] conducted a study on the diversity, richness, and functions of plants in Mamasani pastures of Fars province with different grazing intensities. They reported a significant decrease in declining plants and a significant increase in the growing plants from reference to critical sites. Compared with light and moderate grazing pastures, production and vegetation were also reported to be significantly declined in heavy grazing pasture during the growing season. They concluded that heavy grazing can bring about a significant decrease in production and vegetation coverage of this area.

These results are consistent with those of Tatian et al. [26], who studied the relationship between livestock grazing and vegetation changes in Mako city. They stated that an increase in grazing intensity is correlated with a decrease of crown percentage, a change in plant composition, and a cut in vegetation coverage. The results of the present study show that Artemisia sieberi is the predominant genus in the light and moderate grazing sites whose production is significantly declined in the water trough as the consequence of heavy grazing.

Accordingly, the decline in the production of this plant results from heavy grazing, providing neither opportunity for the proliferation or reproduction of new plants nor space for the presence of more appealing species. Studies have shown that Peganum harmala genus tends to grow surrounding water troughs. It is increased with an increase in the grazing intensity, not by growing in light and moderate grazing postures. Peganum harmala is known as an invasive, unappealing, and toxic plant. These results are consistent with the results of Karimi et al. [27], who introduced improper management and time control over livestock entry and departure as a determinant of vegetation changes in Kohgiluyeh and 
Boyer Ahmad pastures. These findings also confirm the study of Javadi et al. [28] about the effect of livestock grazing on the vegetation composition and diversity of the protected and unprotected grazing areas, showing that the highest coverage percentage belonged to the unprotected area of Class III plants.

\section{The Effect of Plant Residues on the Nitrogen Mineralization Kinetics in Light and Heavy} Grazing Soils

The organic carbon levels of light and moderate grazing soils were significantly different from that of heavy grazing soil, whereas the total nitrogen levels of moderate and heavy grazing soils were significantly different from that of light grazing soil.

In the first week of incubation, the nitrogen mineralization trend in treated soils of both regions (light and heavy grazing) with $50 \%$ to $100 \%$ Artemisia sieberi residues showed strong immobilization. This trend followed a slower rate by the third week and then continued with an increasing rate. Given that the light grazing area has been protected against livestock for more than 20 years, the tentative decrease in mineral nitrogen at the start of incubation seems to have occurred after the provided conditions for plant residue decomposition. In other words, suitable conditions during incubation in terms of temperature and humidity make it possible for Artemisia sieberi and Peganum harmala residues to be decomposed. As Artemisia sieberi residues are of poor quality (high carbon to nitrogen and lignin to nitrogen ratios), the microbial community of soil heterotrophs uses and decomposes mineral nitrogen storage. The use of mineral nitrogen storage by the soil heterotrophic community causes nitrogen transfer from the mineral phase into the microbial biomass. In the first three weeks of incubation, the nitrogen mineralization process falls and mineral nitrogen declines. After this time, the limited supply of required carbon by microbes stops the immobilization process. Then, the decomposition of microbial biomass releases the organic nitrogen and changes it into mineral nitrogen. This justifies the increase in mineral nitrogen levels after the third week of incubation. In comparison with 100\% Artemisia sieberi, 100\% Peganum harmala residues increased nitrogen mineralization due to higher nitrogen and lower $\mathrm{C} / \mathrm{N}$.

Therefore, with an increase in grazing intensity and Peganum harmala percentage in vegetation, pure nitrogen mineralization is increased. This finding is in agreement with the findings of Trincetrol et al. [29], who found that residues with a $\mathrm{C} / \mathrm{N}$ ratio in the range of 24 to 150 showed pure immobilization and residues with a ratio of less than 24 showed pure mineralization. Similarly, this finding is in line with that of Reeder [30], reporting a growth in the total mass of mineral nitrogen for heavy grazing compared with light grazing. However, it is inconsistent with the findings of Frank et al. [31] and Riahi and Raisi [32], expressing that an increase of grazing intensity is associated with a decrease in pure nitrogen mineralization. This can be explained by the difference between their study area and ours in the type of invasive genus of the heavy grazing region.

The highest and the lowest values of 168.38 and $10.4 \mathrm{gr} / \mathrm{kg}$ for Nm$/ \mathrm{i}$ were respectively obtained from $100 \%$ Peganum harmala and $100 \%$ Artemisia sieberi treatments in light grazing soil. The results obtained from the interrelation of time and treatments revealed their separate effects on the pure nitrogen mineralization in light and heavy grazing regions. For both regions, the highest and the lowest pure nitrogen mineralization correspond to $100 \%$ Peganum harmala treatment in week zero and $100 \%$ Artemisia sieberi treatment in week three, respectively. These results support the results of Jafari and Raeesi [33], who found that the effect of plant residues on nitrogen mineralization is conditional to chemical quality and the carbon-to-nitrogen ratio of residues. 


\section{Conclusions}

In sum, the study findings suggest that a high intensity of livestock grazing causes changes in the composition of vegetation leading to a reduction in vegetation coverage, the removal of some species, and the addition of some unappealing species including Peganum harmala in the grassland. These changes influence nitrogen mineralization kinetics, affecting the amount and speed of this process in this pasture. Additionally, there is a heavy loss of this element and the consequent loss of necessary cations that, in the long run, reduce soil fertility in the heavy grazing grassland. This can be attributed to the lower vegetation coverage and thus low nitrogen absorption as well as more livestock traffic and thus high soil erosion rate. Hence, more attention should be paid to implementing effective strategies for proper management and renewal of vegetation coverage, enhancing the species useful for grazing, those useful for humans, and in particular the wild crops related to environmental sustainability [34-36].

Author Contributions: Conceptualization, A.R. and S.G.; data curation, Z.K.; formal analysis, Z.K.; investigation, Z.K. and M.A.; methodology, Z.K.; project administration, A.R.; resources, A.R. and S.G.; supervision, A.R. and S.G.; validation, A.R., M.A. and S.G.; writing-original draft, Z.K. and A.R.; writing-review and editing, A.R., M.A. and S.G. All authors have read and agreed to the published version of the manuscript.

Funding: This research received no external funding.

Institutional Review Board Statement: Not applicable.

Informed Consent Statement: Not applicable.

Data Availability Statement: Not applicable.

Acknowledgments: The authors would like to express their appreciation to the Department of Natural Resources of Yazd University for its support for this project.

Conflicts of Interest: The authors declare that there are no conflict of interest.

\section{References}

1. Crawley, M.J. Herbivory: The Dynamics of Plant-Animal Interactions; Blackwell Scientific Publications: Oxford, UK, 1983; pp. 420-439.

2. Noy-Meir, I.; Gutman, M.; Kaplan, Y. Responses of Mediterranean grassland plants to grazing and protection. J. Ecol. 1989, 77, 290-310. [CrossRef]

3. Perrino, E.V.; Magazzini, P.; Musarella, C.M. Management of grazing "buffalo" to preserve habitats by Directive $92 / 43$ EEC in a wetland protected area of the Mediterranean coast: PaludeFrattarolo, Apulia, Italy. Euro-Mediterr. J. Environ. Integr. 2021, 6, 32. [CrossRef]

4. Bell, L.W.; Moore, A.D.; Kirkegaard, J.A. Evolution of crop-livestock integration systems that improve farm productivity and environmental performance in Australia. Eur. J. Agron. 2013, 57, 10-20. [CrossRef]

5. Tahmasebi, P. Analysis of Rangeland Ecosystems; Pelk Publications: Tehran, Iran, 2009; pp. 148-203.

6. Reeder, J.D.; Schuman, G.E. Influence of livestock grazing on C sequestration in semi-arid mixed-grass and short-grass rangelands. Environ. Pollut. 2002, 116, 457-463. [CrossRef]

7. Snyman, H.A.; Preez, C.C. Rangeland degradation in a semi-arid South Africa-II: Influence on soil quality. J. Arid Environ. 2005, 60, 483-507. [CrossRef]

8. Han, G.; Hao, X.; Zhao, M.; Wang, M.; Ellert, B.H.; Willms, W.; Wang, M. Effect of grazing intensity on carbon and nitrogen in soil and vegetation in a meadow steppe in Inner Mongolia Agriculture. Ecosyst. Environ. 2008, 125, 21-32. [CrossRef]

9. Hart, S.; Nason, G.; Myrold, D.; Perry, D. Dynamics of gross nitrogen transformation an old-growth forest: The carbon connection. Ecology 1994, 75, 880-891. [CrossRef]

10. Corbeels, M.; Oconnell, A.M.; Grove, T.S.; Mendham, D.S.; Rance, S.J. Nitrogen release from eucalypt leaves and legume residues as influenced by their biochemical and degree of contact with soil. Plant Soil. 2003, 250, 15-28. [CrossRef]

11. Baghestani-Maybodi, N. An Investigation into Short-Term Effects of Different Intensities of Goat Grazing: Some Characteristics of Vegetation and Livestock Performance in Steppe Pastures of Yazd. Ph.D. Thesis, University of Tehran, Tehran, Iran, 2003; pp. 198-216.

12. Dashti, M. Justification Studies on Renewable Natural Resources (Nodoushan District); Iranian Forests and Rangelands Organization Publication: Yazd, Iran, 1994; pp. 85-137. 
13. Sheidai, G.; Nemati, N. Modern Rangeland and Forage Production in Iran; Iranian Forests and Rangelands Organization Publication: Tehran, Iran, 1978; pp. 46-124.

14. Rashtian, A.; Mesdaghi, M.; Boldaji, F.; Barani, H. Determination of preference value of seven important range species in steppe region of Yazd province (Case study: Nodoushan rangelands). J. Agric. Sci. Nat. Resour. 2010, 16, $215-227$.

15. Koochaki, A. The Exploitation of Rangeland Shrubs; Ferdouwsi University Press: Mashhad, Iran, 2005; pp. 140-159.

16. Moghadam, R. Range and Rangeland Management; University of Tehran Press: Tehran, Iran, 2008; pp. $183-247$.

17. Mesdaghi, M. Rangeland Management in Iran; Imam Reza Publication: Mashhad, Iran, 2003; pp. 74-164.

18. Hesse, P.R. A Text Book of Soil Chemical Analysis; John Murray: London, UK, 1971; pp. 37-86.

19. Nelson, D.W.; Sommers, L.P. Total carbon, organic carbon and organic matter. Methods Soil Anal. Part 2 Chem. Microbiol. Prop. 1983, 9, 539-579.

20. Bremmer, J.M.; Mulvancey, C.S. Total Nitrogen. Methods Soil Anal. Part 2 Chem. Microbiol. Prop. 1965, 9, $1149-1178$.

21. Goering, H.K.; Van Soests, P.J. Forage Fiber Analysis; USAD Hand book, NO. 397; US. Government Printing Office: Washington DC, USA, 1970; pp. 173-276.

22. Nourbakhsh, F. Fate of carbon and nitrogen from plant residue decomposition in a calcareous soil. Plant Soil. Environ. 2006, 52, 137-140. [CrossRef]

23. Keeney, D.R.; Nelson, D.W. Nitrogen-inorganic forms. Methods Soil Anal. Part 2 Chem. Microbiol. Prop. 1983, 9, $643-698$.

24. Mirjalili, A.; Heydari, G.; Baghestani Meybodi, N.; Rastgar, S. Causal Analysis of Factors Affecting the Downturn of Traditional Livestock Husbandry in Local Communities (Case Study: Nodoushan Yazd Winter Pastures). J. Rural. Res. 2021, 12, $140-155$.

25. Gholami, P.; Ghorbani, J.; Shokri, M. Variations of diversity, richness and functional groups of vegetation in different intensities of livestock grazing (Case study: Mahour Mamasani rangelands, Fars province). Iran. J. Range Desert Res. 2011, 18, $662-675$.

26. Tatian, M.; Tamarta, R.; Ghordoi-Milan, G.; Saeedi-Garaghani, H. Investigating the effect of livestock grazing on changes in vegetation in Mako city. J. Anim. Sci. Res. Instit. Iran. 2014, 12, 65-78.

27. Karimi, G.; Mozafari, S.; Nikbakht, M. Effect of range and livestock management on vegetation of Margon station in Kohkiloyeh and Boyerahmad province, Iran. Iran. Range Desert Res. 2009, 16, 353-361.

28. Javadi, S.A.; Jafari, M.; Azarnivand, H.; Zahedi Amiri, G. Investigation of Grazing Effects on Plant Composition and Diversity of Lar Rangeland. In Proceedings of the third National Congress on Range and Range Management of Iran, Tehran, Iran, 7 September 2004; pp. 702-707.

29. Trinsoutrol, I.; Recouse, S.; Bents, B.; Lineres, M.; Chenebey, D.; Nicolardot, B. Biochemical quality of crop residues and carbon and nitrogen mineralization kinetics under nonliming Nitrogen condition. Soil Sci. Soc. Am. J. 2000, 64, 91-926.

30. Reeder, J.D.; Schuman, G.E.; Morgan, J.A.; Lecain, D.R. Response of organic and inorganic carbon and nitrogen to long-term grazing of the short grass Steppe. Environ. Manag. 2004, 33, 485-495. [CrossRef]

31. Frank, D.A.; Evans, R.D. Effects of native grazers on grassland N cycling in Yellowstone National Park. Ecology 1997, 78, 2238-2248. [CrossRef]

32. Riahi, M.; Raeesi, F. Effects of livestock grazing on carbon, nitrogen and soil microbial biomass in some pastures of Chaharmahal Bakhtiari. J. Water Soil. 2012, 22, 48-56.

33. Jafari, S.; Raeesi, H. Carbon and nitrogen mineralization in a calcareous soil after adding plant and sulfur residues. Iranian. J. Soil Water Res. 2011, 43, 75-86.

34. Perrino, E.V.; Perrino, P. Crop wild relatives: Know how past and present to improve future research, conservation and utilization strategies, especially in Italy: A review. Genet. Resour. Crop. Evol. 2020, 67, 1067-1105. [CrossRef]

35. Maxted, N.; Ford-Lloyd, B.V.; Jury, S.L.; Kell, S.P.; Scholten, M.A. Towards a definition of a crop wild relative. Biodivers. Conserv. 2006, 15, 2673-2685. [CrossRef]

36. Maxted, N.; Ehsan Dulloo, M.; Ford-Lloyd, B.V. (Eds.) Enhancing Crop Gene Pool Use: Capturing Wild Relative and Landrace Diversity for Crop Improvement; CAB International: Wallingford, UK, 2016. 